Universidad

:

BIBLIOTECA

Document downloaded from the institutional repository of the University of Alcala: https://ebuah.uah.es/dspace/

This is a postprint version of the following published document:

Zapata, F. \& García-Ruiz, C., 2017. Analysis of different materials subjected to open-air explosions in search of explosive traces by Raman microscopy. Forensic Science International, 275, pp.57-64.

Available at https://doi.org/10.1016/i.forsciint.2017.02.032

(C) 2017 Elsevier
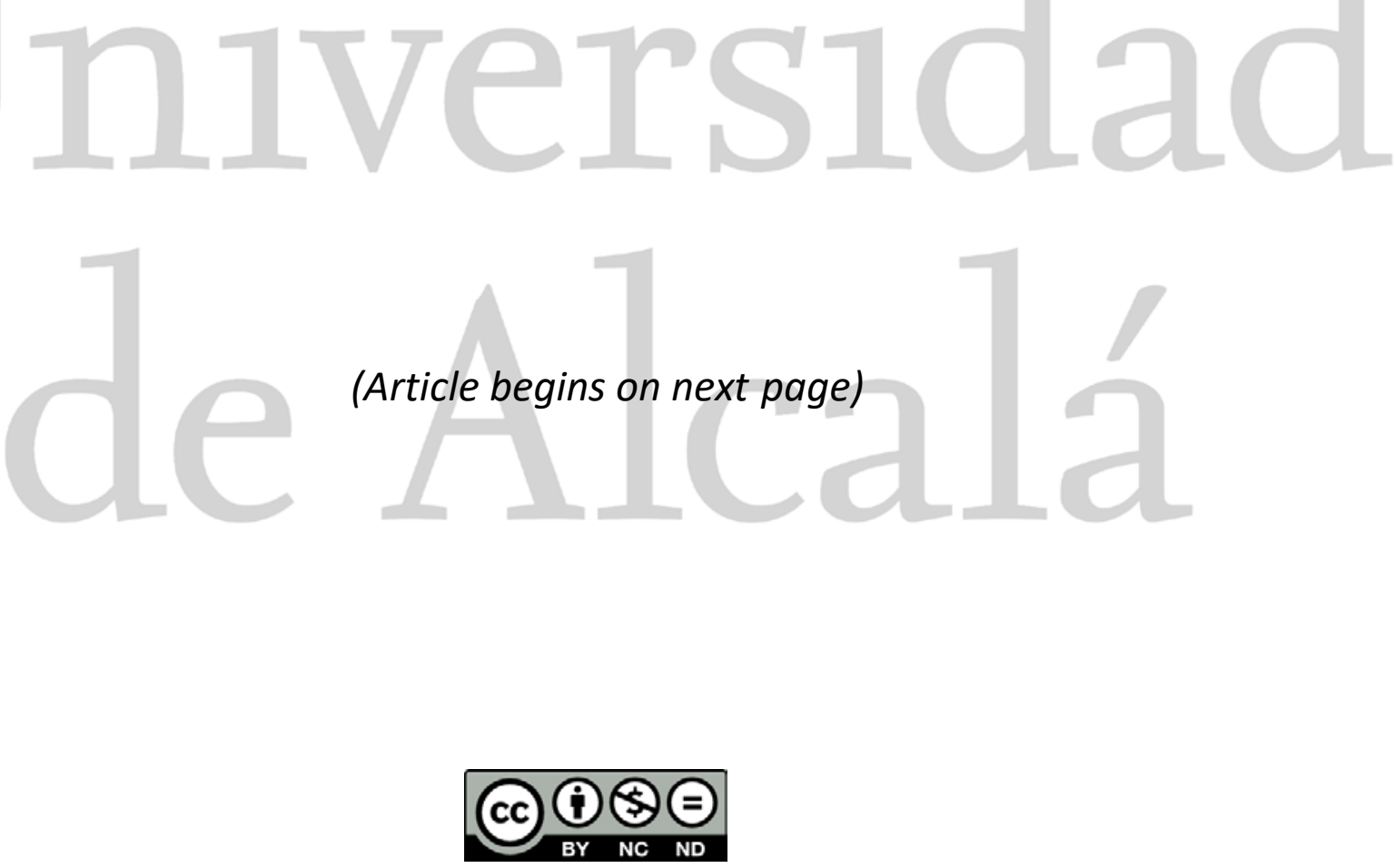

This work is licensed under a

Creative Commons Attribution-NonCommercial-NoDerivatives

4.0 International License. 


\title{
Analysis of different materials subjected to open- air explosions in search of explosive traces by Raman microscopy
}

\author{
Félix Zapata, Carmen García-Ruiz*
}

Department of Analytical Chemistry, Physical Chemistry and Chemical Engineering and Institute of Research in Police Sciences (IUICP), University of Alcalá, Ctra. Madrid-Barcelona km 33.600 28871 Alcalá de Henares (Madrid), Spain

Email: carmen.gruiz@uah.es; felix.zapata@uah.es

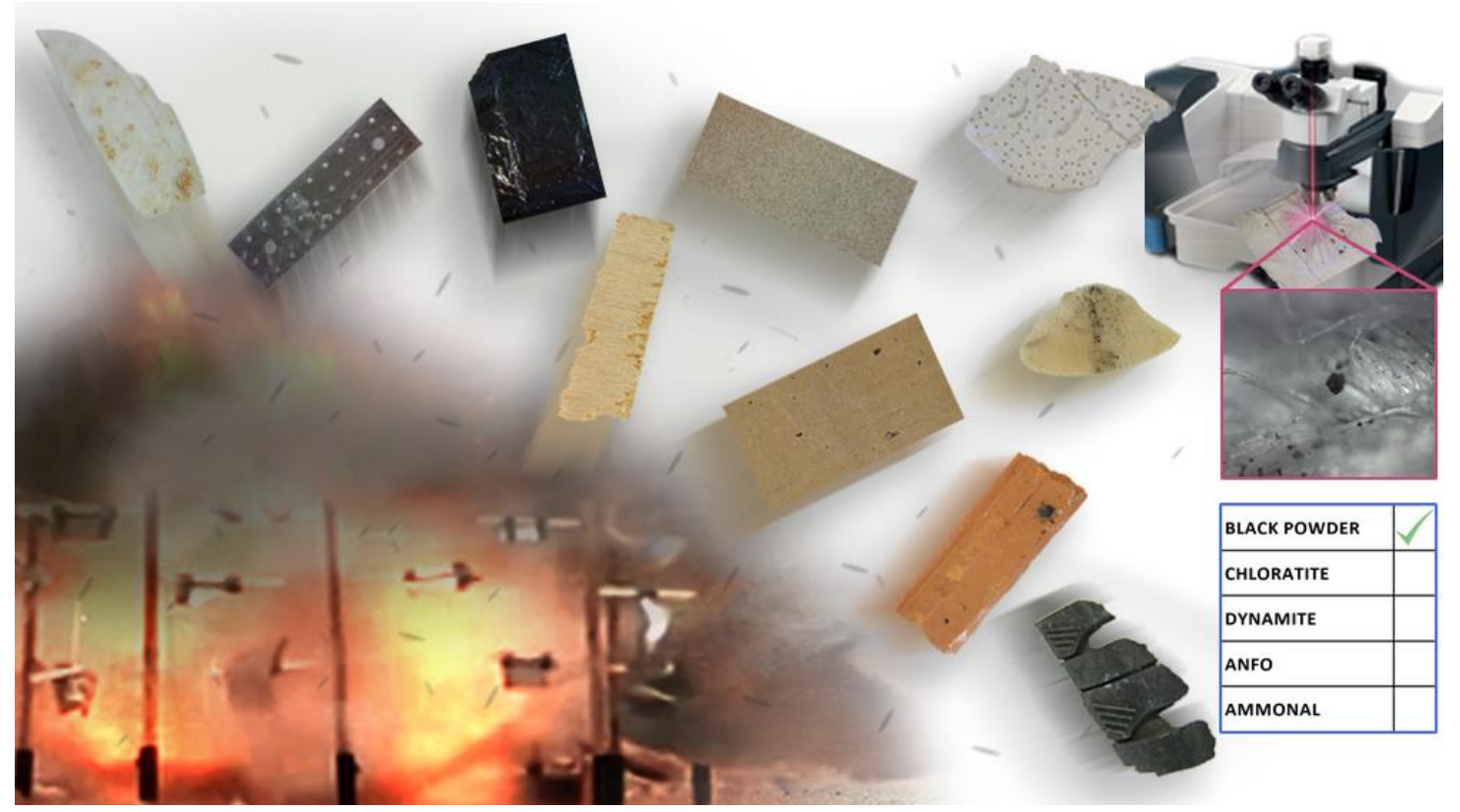

Cite: F. Zapata, C. García-Ruiz, Analysis of different materials subjected to openair explosions in search of explosive traces by Raman microscopy, Forensic Sci. Int. 275 (2017) 57-64. DOI: $\underline{\text { 10.1016/j.forsciint.2017.02.032 }}$

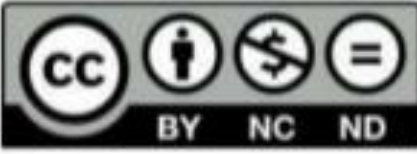




\begin{abstract}
Post-explosion scenes offer such chaos and destruction that evidence recovery and detection of post-blast residues from the explosive in the surrounding materials is highly challenging and difficult. The suitability of materials to retain explosives residues and their subsequent analysis has been scarcely investigated. Particularly, the use of explosive mixtures containing inorganic oxidizing salts to make improvised explosive devices (IEDs) is a current security concern due to their wide availability and lax control. In this work, a wide variety of materials such as glass, steel, plywood, plastic bag, brick, cardboard or cotton subjected to open-air explosions were examined using confocal Raman microscopy, aiming to detect the inorganic oxidizing salts contained in explosives as black powder, chloratite, dynamite, ammonium nitrate fuel oil and ammonal. Postblast residues were detected through microscopic examination of materials surfaces. In general, the more homogeneous and smoother the surface was, the less difficulties and better results in terms of identification were obtained. However, those highly irregular surfaces were the most unsuitable collectors for the posterior identification of explosive traces by Raman microscopy. The findings, difficulties and some recommendations related to the identification of post-blast particles in the different materials studied are thoroughly discussed.
\end{abstract}

Keywords: ANFO; Black powder; Dynamite; Material surfaces; Post-blast residues; Raman microscopy. 


\section{Introduction}

Amongst the large variety of explosive compositions, explosive mixtures based on oxidizing energetic salts are certainly the explosives most frequently used by civilians (non-militaries) to carry out, not only legitimate commercial purposes such as demolitions and pyrotechnics, but also to commit criminal actions [1-5]. As a result of the wide availability, easy acquisition and lax control of these explosives precursors, oxidizing energetic salts are usually employed by dissidents, extremists and terrorists in the elaboration of improvised explosive devices (IEDs). The mixture of oxidizing energetic salts with fuels produces explosive compositions that can be used as explosive charge in IEDs such as black powder, dynamite or ammonium nitrate fuel oil (ANFO) $[1,3]$. Oxidizing salts commonly used in these explosive mixtures are nitrate and chlorate salts [1,3], which may be combined (in different proportions) with a large variety of fuels such as charcoal, fuel oil or sugar. However, it is important to highlight that whatever the composition is, the oxidizing salt is usually the main and major component in the mixture to ensure the consumption of the fuel and cause the consequent explosion. As a result, post-blast residues from these explosives mostly consist of non-reacted remains of the oxidizing salt [6-12]. Due to their ionic nature, forensic laboratories routinely analyse them by either capillary electrophoresis or ion chromatography, and a wide research involving these two techniques for the analysis of inorganic oxidizing salts from explosives have been published [11-20]. Nevertheless, both techniques are destructive, time-consuming, require a sample treatment and dissociate the salt into its ions. On the contrary, spectroscopic techniques such as Raman spectroscopy has shown an interesting potential for the identification of salts in explosives [10,12,21-24]. However, the material in which post-blast particles of these oxidizing salts are adsorbed during an explosion, may play an important (and scarcely studied) role in both evidence recovery and spectroscopic measurements [25]. Different materials are expected to offer a different adsorption in relation to the capture of those post-blast particles and, thus, some materials are expected to be more efficient than others. The investigation of this aspect is crucially important for providing forensic investigators know how on the different materials they should preferentially collect during evidence recovery. In addition, each material has a characteristic spectral signature according to its composition, which may occasionally overlap the characteristic bands of the studied salts. This fact may hinder the spectroscopic detection and identification of post-blast particles, especially when no 
focusing system is used to exclusively analyse a selected post-blast particle. In this respect, microscopy coupled to Raman spectroscopy has demonstrated to be a useful methodology for the microscopic detection and spectroscopic identification of post-blast microscopic particles of explosives on smooth and homogeneous surfaces [10,12]. Particularly, in this previous study accomplished by our group [10], IEDs based on oxidizing-fuel explosive compositions as well as IEDs based on high organic explosives were exploded and their post-blast residues were subsequently analysed over a smooth homogeneous surface. Results revealed that only those IEDs based on oxidizing-fuel explosive compositions left, after their explosion, microscopic non-reacted particles large enough to be detected by confocal Raman microscopy. Nonetheless, there is a large variety of different materials that may be found in post-explosion scenes that makes evidence recovery an extremely complicate process [2]. The knowledge about the suitability of either homogeneous or heterogeneous materials to catch and retain postblast residues that are microscopically perceptible by microscopy is a current forensic need. To this end, in this work, a large variety of materials was subjected to different explosions and the appropriateness of each material for post-blast residues detection using confocal Raman microscopy has been deeply examined.

\section{Materials and experiments}

\subsection{Materials, standards and explosives}

Eleven different materials ( 3 replicates per material except for tyre with only 1 replicate) were placed as explosive trace collectors surrounding each explosion at a distance of 1.5$2 \mathrm{~m}$ in order to study the detection of post blast residues on them. These materials included glass, steel, plastic bag, plywood, chipboard, cardboard, tyre, brick, plaster board, cotton fabric and pig meat, besides the ground from crater. These materials were chosen because they are likely to be found in real terrorist attacks either in the street or within a building. Table 1 collects the size of the pieces of each material.

Standards of potassium nitrate and ammonium nitrate (determined at the end of Section 3.1 for proving their identification profile) were obtained from Sigma-Aldrich in ACS reagent grade $(>99.0 \%)$. 
Table 1. Size of collectors in $\mathrm{cm}$. R refers to the spoke of the tyre (wheel).

\begin{tabular}{|c|c|}
\hline Material & Size (cm) \\
\hline Glass & $18 \times 13$ \\
\hline Metal (steel) & $20 \times 6$ \\
\hline Plastic bag & $30 \times 20$ \\
\hline Plywood & $20 \times 15$ \\
\hline Chipboard & $20 \times 15$ \\
\hline Cardboard & $30 \times 20$ \\
\hline Tyre & $\mathrm{R} \mathrm{30}$ \\
\hline Brick & $25 \times 15 \times 12$ \\
\hline Plasterboard & $20 \times 20$ \\
\hline Cotton fabric & $30 \times 20$ \\
\hline Pig meat & $\sim 15 \times 10$ \\
\hline
\end{tabular}

Five explosions were performed by Spanish EOD specialists using improvised explosive devices (IEDs) made of five different inorganic explosives as those reported in a previous work [10], which contained inorganic oxidizing salts including black powder $(75 \%$ potassium nitrate), chloratite ( $80 \%$ sodium chlorate), dynamite (66\% ammonium nitrate), ANFO (90\% ammonium nitrate) and ammonal ( $85 \%$ ammonium nitrate).

After each explosion, collectors were recovered and sealed by EOD specialists and were carried out to the laboratory where they were analyzed by confocal Raman microscopy.

\subsection{Instrumentation and analysis}

A Thermo Scientific DXR Raman microscope (Waltham, MA, USA) using the Thermo Scientific Omnic for dispersive Raman 8 software (Waltham, MA, USA) was used to analyze the surfaces of materials. First, each material (collector) was analyzed to establish the representative Raman spectrum of each material and be used as blank. In addition, to set up the characteristic Raman spectrum of each explosive, small samples from the five explosives were analyzed by Raman spectroscopy. Afterwards, the surface of all postblast samples was observed with both the naked eye and microscopically, as explained in previous work [10]. Briefly, after visualizing potential post blast residues, that region was microscopically examined through $10 \times$ and 50x magnification objectives. Afterwards, the alleged post-blast particles were analyzed by Raman spectroscopy in order to confirm or dismiss, based on their Raman spectra, whether they were remains from the explosive. Raman spectra were collected from 2500 to $200 \mathrm{~cm}^{-1}$, accumulating 5 scans of $6 \mathrm{~s}$ per scan and using a $780 \mathrm{~nm}$ excitation wavelength of $10 \mathrm{~mW}$ power. Each Raman spectrum was visually and statistically compared (Pearson correlation) with a spectra database previously registered for the explosives. 


\section{Results and discussion}

\subsection{Materials and explosives Raman spectra}

The knowledge of these spectra was necessary to later identify residues from the explosives on these materials. As shown in Figure 1(a), given the Raman conditions, the materials studied mostly provided no relevant Raman signals except brick. In summary, neither steel, plastic bag, chipboard, cardboard nor tyre provided characteristic Raman bands, except for some fluorescence in chipboard. Plywood displayed a weak band (almost worthless) at $1596 \mathrm{~cm}^{-1}$. Plasterboard, besides providing a bit fluorescence, was dominated by a unique prominent band located at $1006 \mathrm{~cm}^{-1} 1$. Though cotton and pig meat displayed some characteristic bands along their spectra, they were little intense. Glass was dominated by two highly distinctive wide prominent bands at 1958 and $1455 \mathrm{~cm}^{-1}$. Finally, brick displayed, unlike previous materials, a large number of bands, some of them, noticeably intense such as those at 1668 and $1460 \mathrm{~cm}^{-1}$.

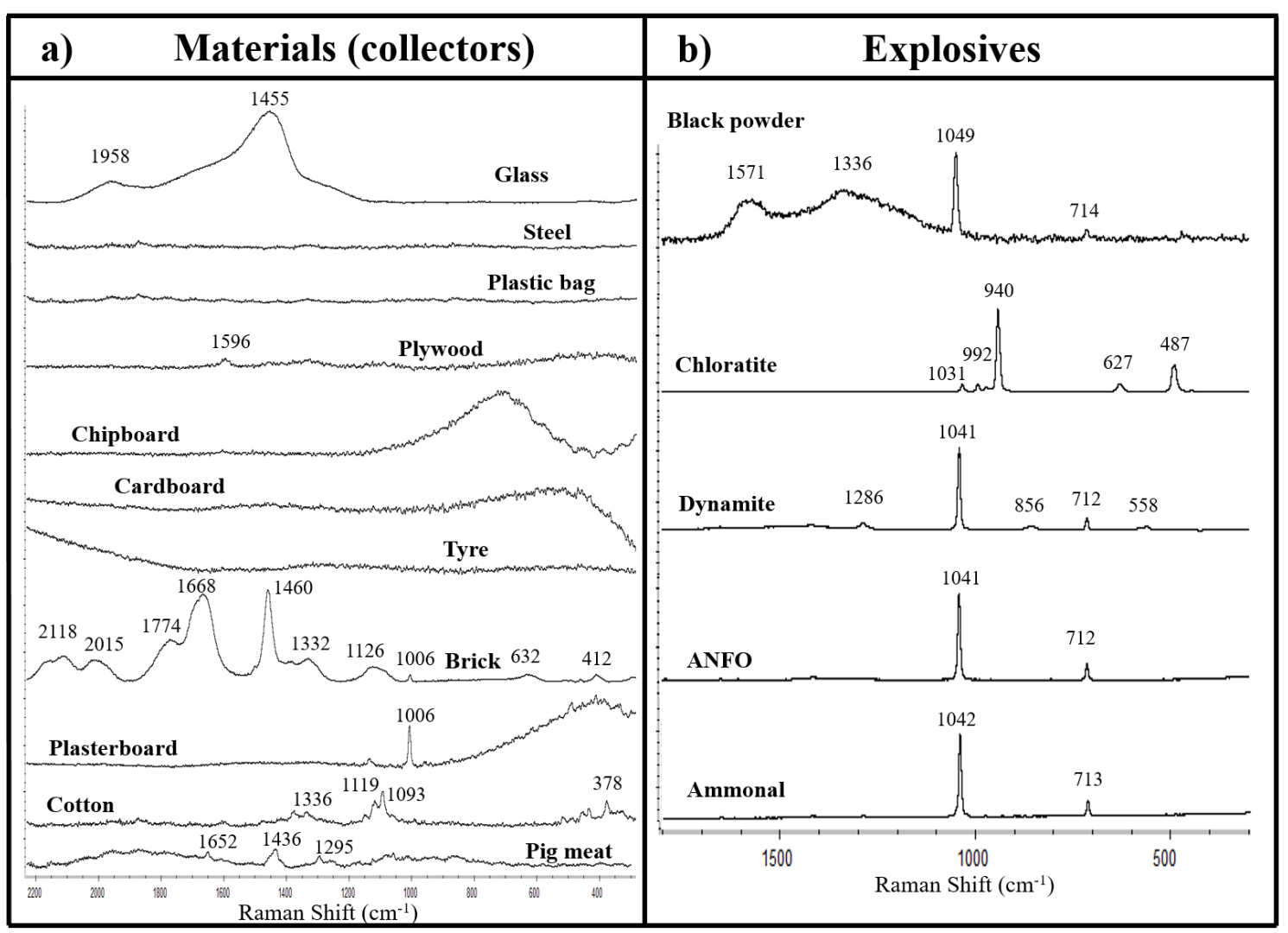

Figure 1. Raman spectra of materials (a) and explosives (b) studied in this work. Raman conditions: laser at $780 \mathrm{~nm}, 14.0 \mathrm{~mW}, 10 \times$ magnification objective, 6 acquisitions of $5 \mathrm{~s}$ per acquisition. Materials spectra are displayed on a common scale +offset (a), in order to compare the potential interference each material may cause as background using the selected Raman 
conditions. On the contrary, explosives spectra have been normalized +offset (b) in order to clarify the characteristic bands that enable their identification.

On the contrary, explosives were clearly characterized by the Raman spectra of their respective oxidizing salts, as shown in Figure 1(b). This result was not unexpected since oxidizing salts are the major component in these explosives mixtures. What was an unexpected result was the low Raman signals provided by most materials because of the fact that Raman spectroscopy is being proved as a suitable technique to characterize a wide variety of materials. At the selected Raman conditions only those highly Raman active compounds and Raman active vibrations such as those in nitrates and chlorates were properly deter- mined. This result was highly favorable because it meant that most materials would not overlap the Raman spectra from explosives.

As shown in Figure 1(b), the different oxidizing salts from explosives (potassium nitrate, sodium chlorate and ammonium nitrate) are easily identified by Raman spectroscopy according to their different Raman spectra. Thus, as reported in our previous work [10]: black powder was characterized by the Raman bands of potassium nitrate (1049 and 714 $\mathrm{cm}^{-1}$ ) and charcoal (1571 and $1336 \mathrm{~cm}^{-1}$ ); sodium chlorate from chloratite displayed its main characteristic bands at 940, 627 and $487 \mathrm{~cm}^{-1}$ and ammonium nitrate from dynamite, ANFO and ammonal provided its respective bands at around 1041 and 712 $\mathrm{cm}^{-1}$. Interestingly, weak bands due to nitroglycol were also observed in the dynamite spectrum.

It should be noted that the discrimination between potassium and ammonium nitrates according to the observed shift of $7-8 \mathrm{~cm}^{-1}$ of their main nitrate bands may be difficult from a practical point of view, especially when portable Raman spectrometers with low resolution are used. Thus, an additional proof to solve this question can be accomplished at the laboratory. One particle of potassium nitrate standard can be placed in contact with one particle of ammonium nitrate standard, both on a microscope slide. Then, Raman microscope needs to be focused just on the contact between the two particles. Under these conditions, if the Raman system has enough spectral resolution, spectra as those displayed in Figure 2 should be obtained. 


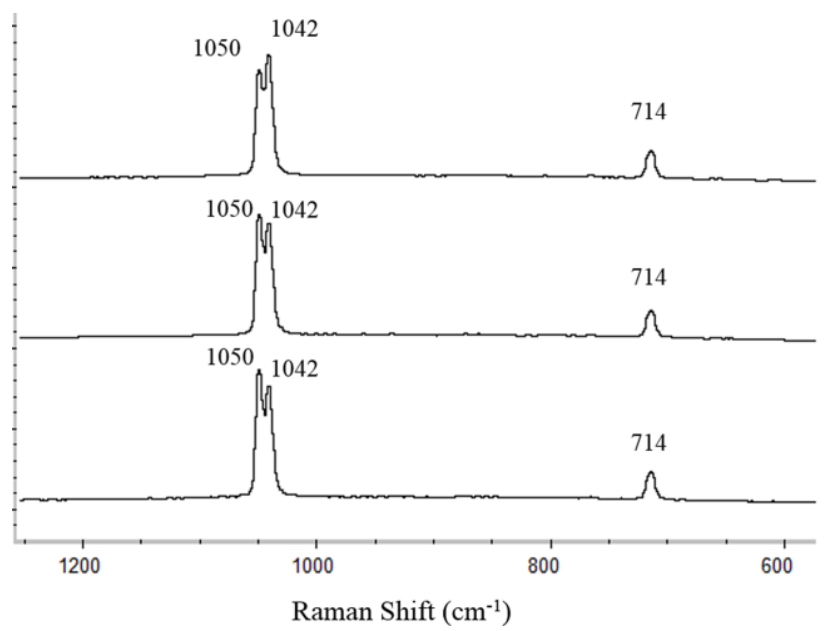

Figure 2. Simultaneous identification of potassium nitrate and ammonium nitrate by focusing three nearby spots along the frontier between two particles of potassium and ammonium nitrate. Raman conditions as in Figure 1.

The characteristic Raman bands of each nitrate (potassium and ammonium) need to be clearly visible and distinguishable according to their bands located at 1050 and 1042 $\mathrm{cm}^{-1}$, respectively. This approach allows to confirm if the simultaneous identification and discrimination of potassium and ammonium nitrates is achievable using the Raman instrument available in the laboratory. That is, this procedure can be a rapid and easy way to check whether our Raman instrument has enough resolution to differentiate both nitrates or not.

\subsection{Detection of explosive components on materials subjected to open-air explosions}

Post-blast residues from different explosions were analyzed in order to study the suitability of each material (collector) for postblast residues detection. The positive/negative results achieved in the detection of post-blast non-reacted particles from each explosive on the different materials studied are summarized in Table 2. A positive result involved that at least one post-blast particle was detected; though, that result was uncommon and the most usual positive result involved detecting numerous post-blast particles of the oxidizing salt along the replicate. On the other hand, a negative result involved that no post-blast particle was detected in that replicate.

A comprehensive overview of each material including useful tips and the difficulties overcome during their analysis by confocal Raman microscopy is described below. According to the visual characterization of their surface, the eleven materials were classified to facilitate the interpretation of results into four classes: homogeneous, heterogeneous, highly irregular and biological. 
Table 2. Results of post-blast particles detection from explosives on the replicates of the eleven different materials (collectors) studied in this work.

\begin{tabular}{|c|c|c|c|c|c|c|c|c|c|c|c|}
\hline \multirow{4}{*}{$\begin{array}{c}\text { Material (collector) } \\
\text { Glass }\end{array}$} & \multirow{3}{*}{$\begin{array}{c}\text { Replicate (R) } \\
\text { R1 } \\
\text { R2 }\end{array}$} & \multicolumn{2}{|c|}{ Black powder } & \multicolumn{2}{|c|}{ Chloratite } & \multicolumn{2}{|c|}{ Dynamite } & \multicolumn{2}{|c|}{ ANFO } & \multicolumn{2}{|c|}{ Ammonal } \\
\hline & & + & \multirow{3}{*}{$2 / 3$} & + & \multirow{3}{*}{$3 / 3$} & - & \multirow{3}{*}{$0 / 3$} & - & \multirow{3}{*}{$2 / 3$} & + & \multirow{3}{*}{$3 / 3$} \\
\hline & & + & & + & & - & & + & & + & \\
\hline & $\mathrm{R} 3$ & - & & + & & - & & + & & + & \\
\hline \multirow{3}{*}{ Steel } & $\mathrm{R} 1$ & + & \multirow{3}{*}{$2 / 3$} & + & \multirow{3}{*}{$2 / 3$} & - & \multirow{3}{*}{$0 / 3$} & + & \multirow{3}{*}{$3 / 3$} & - & \multirow{3}{*}{$0 / 3$} \\
\hline & $\mathrm{R} 2$ & + & & + & & - & & + & & - & \\
\hline & R3 & - & & - & & - & & + & & - & \\
\hline \multirow{3}{*}{ Plastic bag } & $\mathrm{R} 1$ & - & \multirow{3}{*}{$1 / 3$} & + & \multirow{3}{*}{$2 / 3$} & + & \multirow{3}{*}{$2 / 3$} & + & \multirow{3}{*}{$3 / 3$} & - & \multirow{3}{*}{$2 / 3$} \\
\hline & $\mathrm{R} 2$ & + & & - & & + & & + & & + & \\
\hline & R3 & - & & + & & - & & + & & + & \\
\hline \multirow{3}{*}{ Plywood } & $\mathrm{R} 1$ & - & \multirow{3}{*}{$2 / 3$} & + & \multirow{3}{*}{$3 / 3$} & - & & + & & + & \\
\hline & $\mathrm{R} 2$ & + & & + & & - & $1 / 3$ & + & $3 / 3$ & + & $2 / 3$ \\
\hline & R3 & + & & + & & + & & + & & - & \\
\hline & $\mathrm{R} 1$ & + & & + & & - & & - & & - & \\
\hline Chipboard & $\mathrm{R} 2$ & + & $3 / 3$ & + & $3 / 3$ & - & $0 / 3$ & - & $0 / 3$ & - & $0 / 3$ \\
\hline & R3 & + & & + & & - & & - & & - & \\
\hline & $\mathrm{R} 1$ & + & & + & & - & & + & & - & \\
\hline Cardboard & $\mathrm{R} 2$ & + & $3 / 3$ & + & $3 / 3$ & - & $0 / 3$ & + & $2 / 3$ & + & $2 / 3$ \\
\hline & R3 & + & & + & & - & & - & & + & \\
\hline Tyre & $\mathrm{R} 1$ & - & $0 / 1$ & + & $1 / 1$ & - & $0 / 1$ & + & $1 / 1$ & - & $0 / 1$ \\
\hline & $\mathrm{R} 1$ & + & & - & & - & & - & & - & \\
\hline Brick & $\mathrm{R} 2$ & + & $3 / 3$ & - & $0 / 3$ & - & $0 / 3$ & - & $0 / 3$ & - & $0 / 3$ \\
\hline & R3 & + & & - & & - & & - & & - & \\
\hline & $\mathrm{R} 1$ & + & & - & & - & & - & & - & \\
\hline Plasterboard & $\mathrm{R} 2$ & + & $3 / 3$ & + & $1 / 3$ & - & $0 / 3$ & + & $1 / 3$ & - & $0 / 3$ \\
\hline & R3 & + & & - & & - & & - & & - & \\
\hline & $\mathrm{R} 1$ & + & & - & & - & & - & & - & \\
\hline Cotton fabric & $\mathrm{R} 2$ & + & $2 / 3$ & - & $1 / 3$ & - & $0 / 3$ & - & $0 / 3$ & - & $0 / 3$ \\
\hline & R3 & - & & + & & - & & - & & - & \\
\hline & $\mathrm{R} 1$ & + & & - & & - & & - & & - & \\
\hline Pig meat & $\mathrm{R} 2$ & + & $3 / 3$ & - & $0 / 3$ & - & $0 / 3$ & - & $0 / 3$ & - & $0 / 3$ \\
\hline & R3 & + & & - & & - & & - & & - & \\
\hline
\end{tabular}

\subsubsection{Homogeneous surfaces}

3.2.1.1. Glass. Glass substrates provided a homogeneous and smooth surface in which both visual and microscopic detection of post-blast residues was quite straightforward. Those foreign particles added on glass were determined by Raman spectroscopy and provided two different spectra: the spectrum of ground or the spectrum of one of the explosive components, as displayed in Figure 3. Thus, spectra allowed to confirm whether those particles were post-blast non-reacted particles from the explosive or particles from the ground. Particles from the ground displayed a characteristic spectrum dominated by one main band located at $1087 \mathrm{~cm}^{-1}$ which was due to calcite (calcium carbonate). This was confirmed by testing a standard of calcium carbonate. The reason why particles from 
ground were found on the surface of materials is probably explained by the fact that ground from crater blew up during the explosion and some particles flew off up to the materials (collectors).
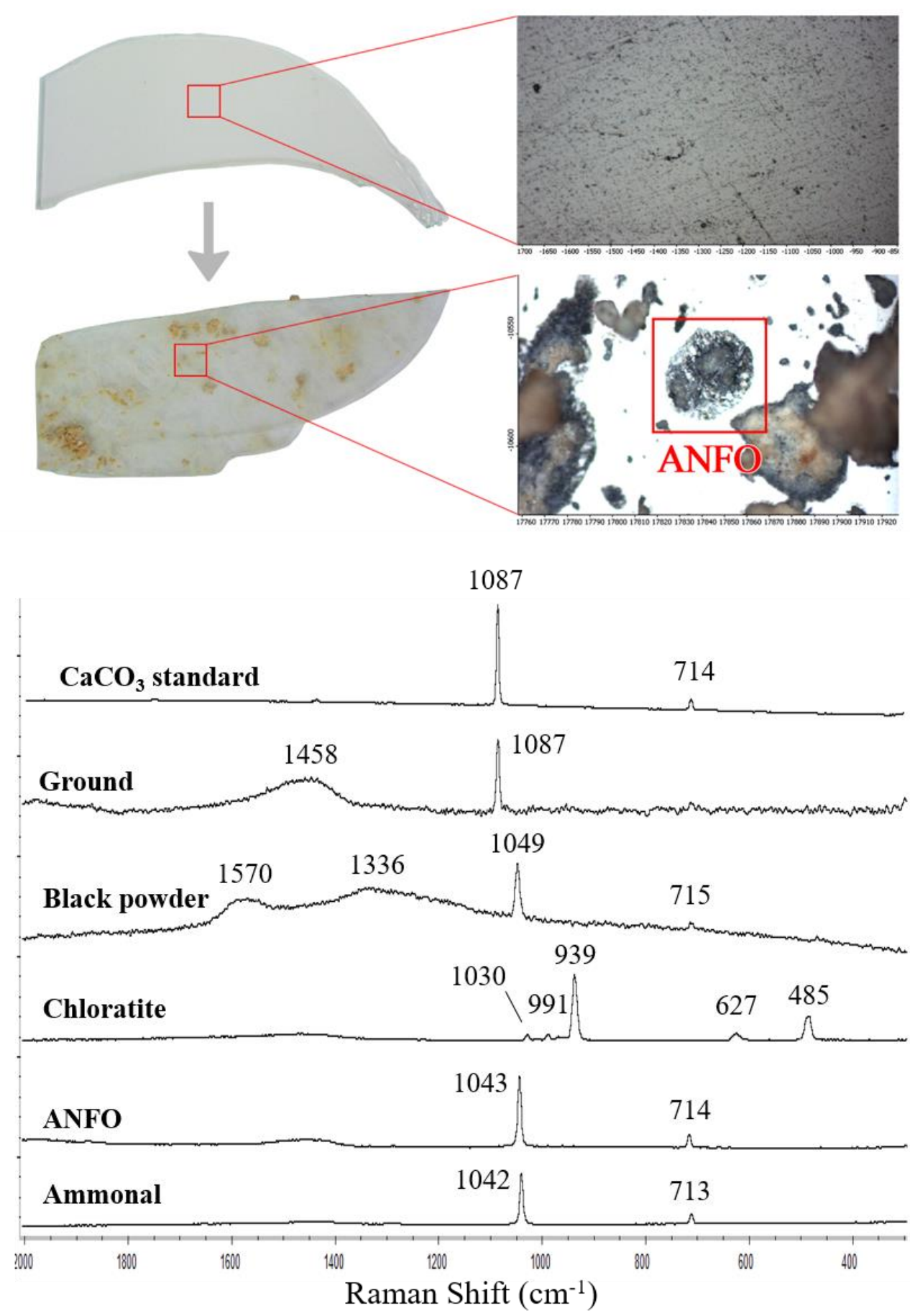

Figure 3. Microscopic examination of glass surface and post-blast residues, and Raman spectra of the calcium carbonate standard and the post-blast residues from ground and from the four explosives detected on glass collectors: black powder, chloratite, ANFO and ammonal. Raman conditions as in Figure 1. 
Although this phenomenon (particles of ground on the surface of materials) was observed for almost all the materials, it is not explained for each material to avoid redundancy. Taking into consideration Table 2, which summarizes the results of the detection of postblast residues on the replicates of each material, it can be checked that particles from black powder and ANFO were detected in 2 of the 3 replicates whereas particles from chloratite and ammonal were detected in the three replicates. However, postblast particles from dynamite were not detected on this material surface.

3.2.1.2. Steel. Steel substrates also offered a homogeneous and smooth surface which facilitated the detection of post-blast particles on them. As summarized in Table 2 and Supplementary Figure S1, post-blast particles from black powder, chloratite and ANFO were detected on steel. Post-blast particles from dynamite and ammonal were not detected on steel. Thus, black powder and chloratite were detected on 2 of the 3 replicates whereas ANFO was detected on the 3 replicates. Nonetheless, the Raman spectra provided by post-blast ammonium nitrate particles from ANFO were slightly inaccurate since their characteristic bands usually located at 1041 and $713 \mathrm{~cm}^{-1} 1$ were shifted around $15 \mathrm{~cm}^{-1}$ appearing at 1055 and $730 \mathrm{~cm}^{-1}$. Some studies have revealed the SERS (surface enhanced Raman scattering) effect that steel may provide [26], so this phenomenon could be explained by some sort of SERS interaction between steel surface and ammonium nitrate that may cause the shift. However, the reason why only ammonium nitrate was affected (but not potassium nitrate or sodium chlorate) is unknown. Thus, further investigation focused on comprehending this phenomenon needs to be accomplished. 


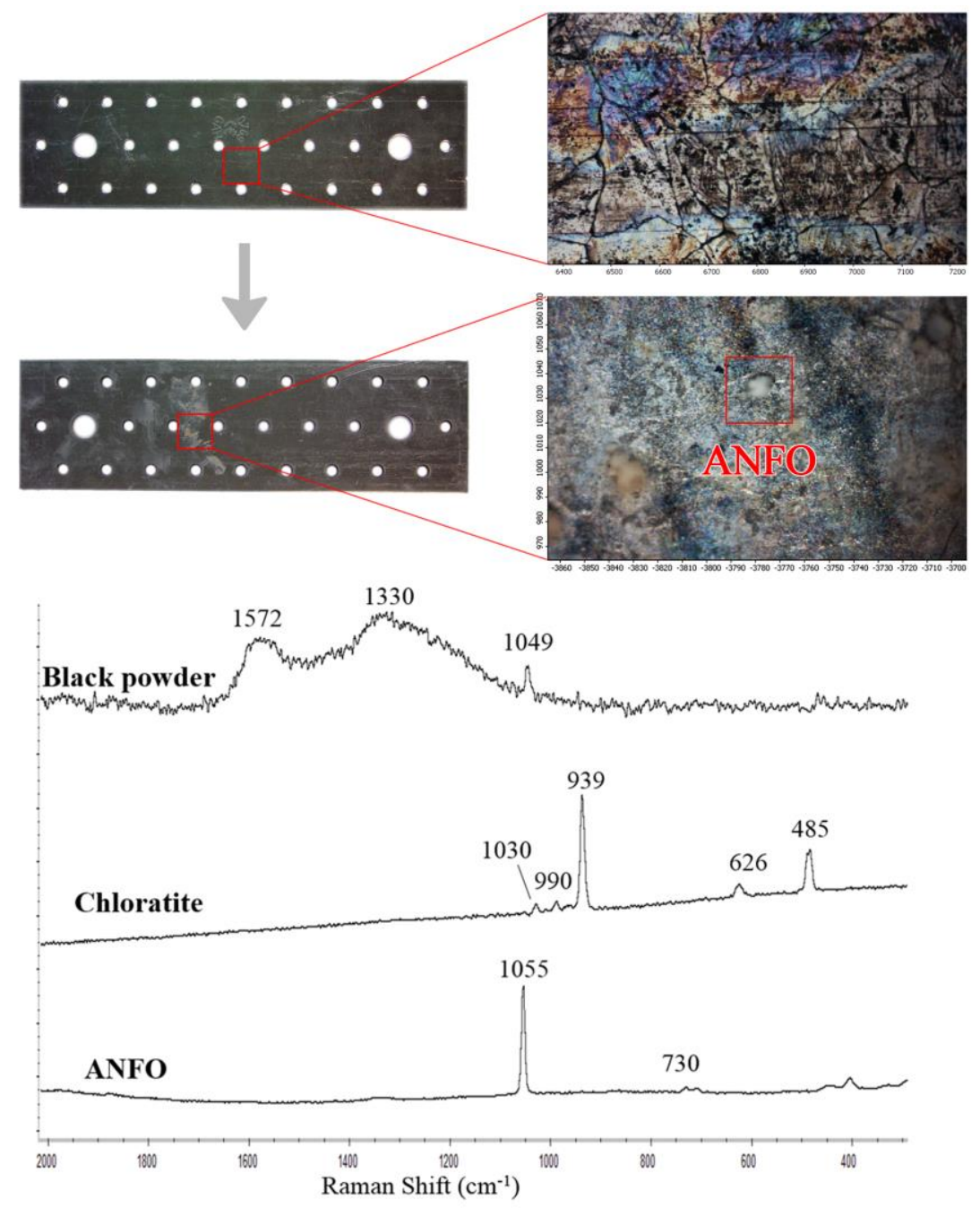

Supplementary Figure S1. Microscopic examination of steel surface (above) and post-blast residues (below) and Raman spectra of the post-blast residues from the three explosives detected on steel collectors: black powder, chloratite and ANFO. Raman conditions as in Figure 1.

3.2.1.3. Plastic bag. Black plastic bags were also highly homogeneous and smooth surfaces in which the detection of white post-blast particles was no trouble. In fact, plastic bags presented an unpredictable result. Although scarce amounts of post-blast particles from explosives were detected on the surface of plastic bags, a large amount of these particles was found inside the plastic bag. Post-blast particles were not found on the outer surface of plastic bags but in the inner surface of the plastic bags, as illustrated in Supplementary Figure S2. In fact, when opening the bags, these particles seemed like spray paint droplets. They were not bound to the second layer, but weakly suspended between the two layers. As hypothesis, this "plastic-bag-effect" may be explained by the fact that particles from the oxidizing salt pierced the first layer of the plastic bag due to 
their residual heat from the explosion, but they were not able of piercing the second layer and, thus, they got trapped between the two layers of the bag. However, further studies would be necessary to confirm this hypothesis.
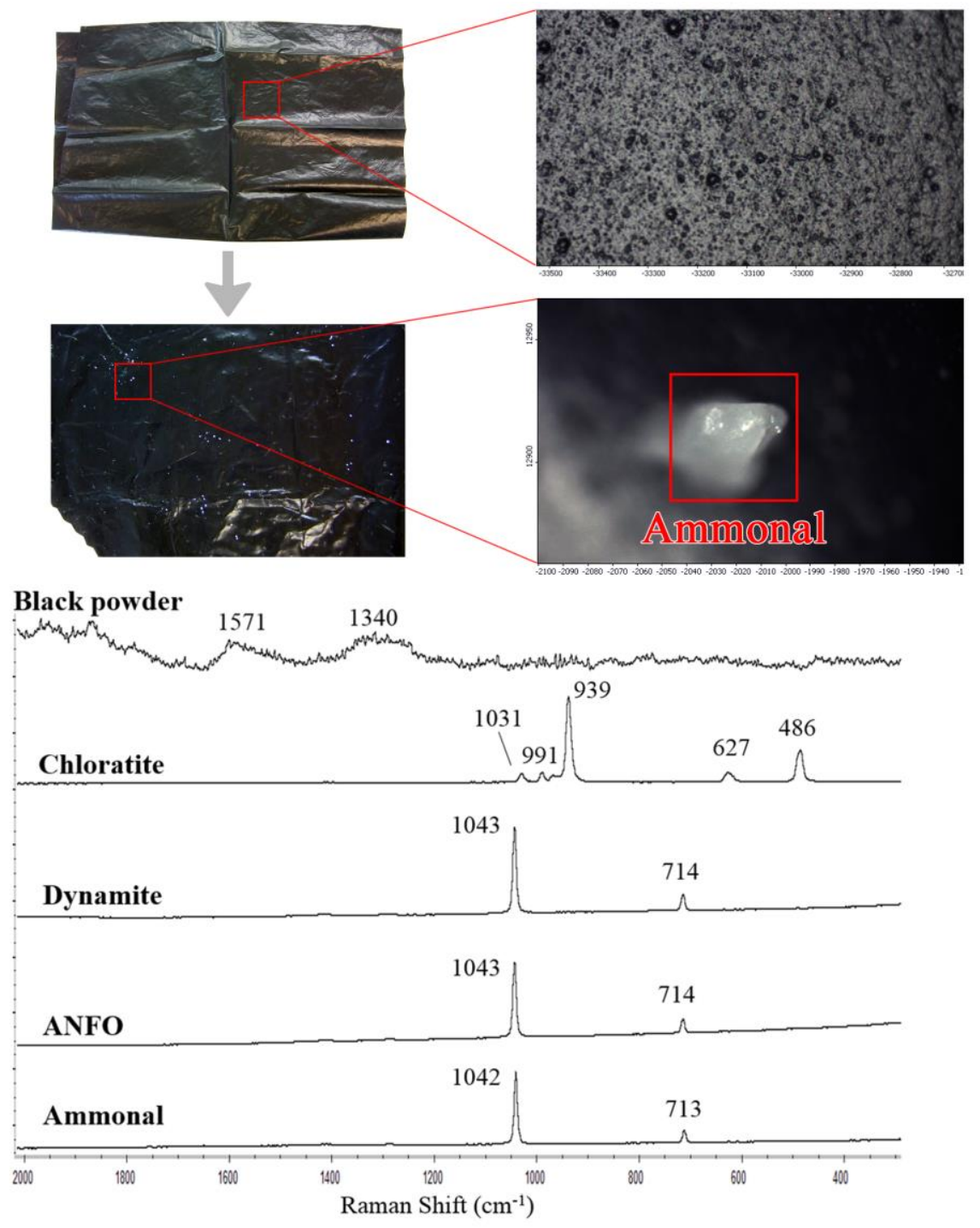

Supplementary Figure S2. Microscopic examination of plastic bag surface (above) and postblast residues (below) and Raman spectra of the post-blast residues from the explosives detected on plastic bag collectors: black powder, chloratite, dynamite, ANFO and ammonal. Raman conditions as in Figure 1.

As shown in Table 2, plastic bags, like plywood, provided the best results since post-blast residues from the five explosives were detected on them. The effect produced by plastic bags likely contributed to trap post-blast particles from the explosives. Post-blast particles from ANFO were identified in the 3 replicates whereas post-blast particles from dynamite, chloratite and ammonal were identified in 2 of the 3 replicates. Finally, post- 
blast particles from black powder were identified in only 1 of the 3 replicates and only charcoal was identified instead of both charcoal and potassium nitrate.

\subsubsection{Heterogeneous surfaces}

3.2.2.1. Plywood. Plywood substrates offered a bit rougher and more heterogeneous surface than the preceding materials. Nevertheless, post-blast particles from explosives were also easily detected on plywood, since they had a great contrast with the plywood pattern as shown in Supplementary Figure S3.

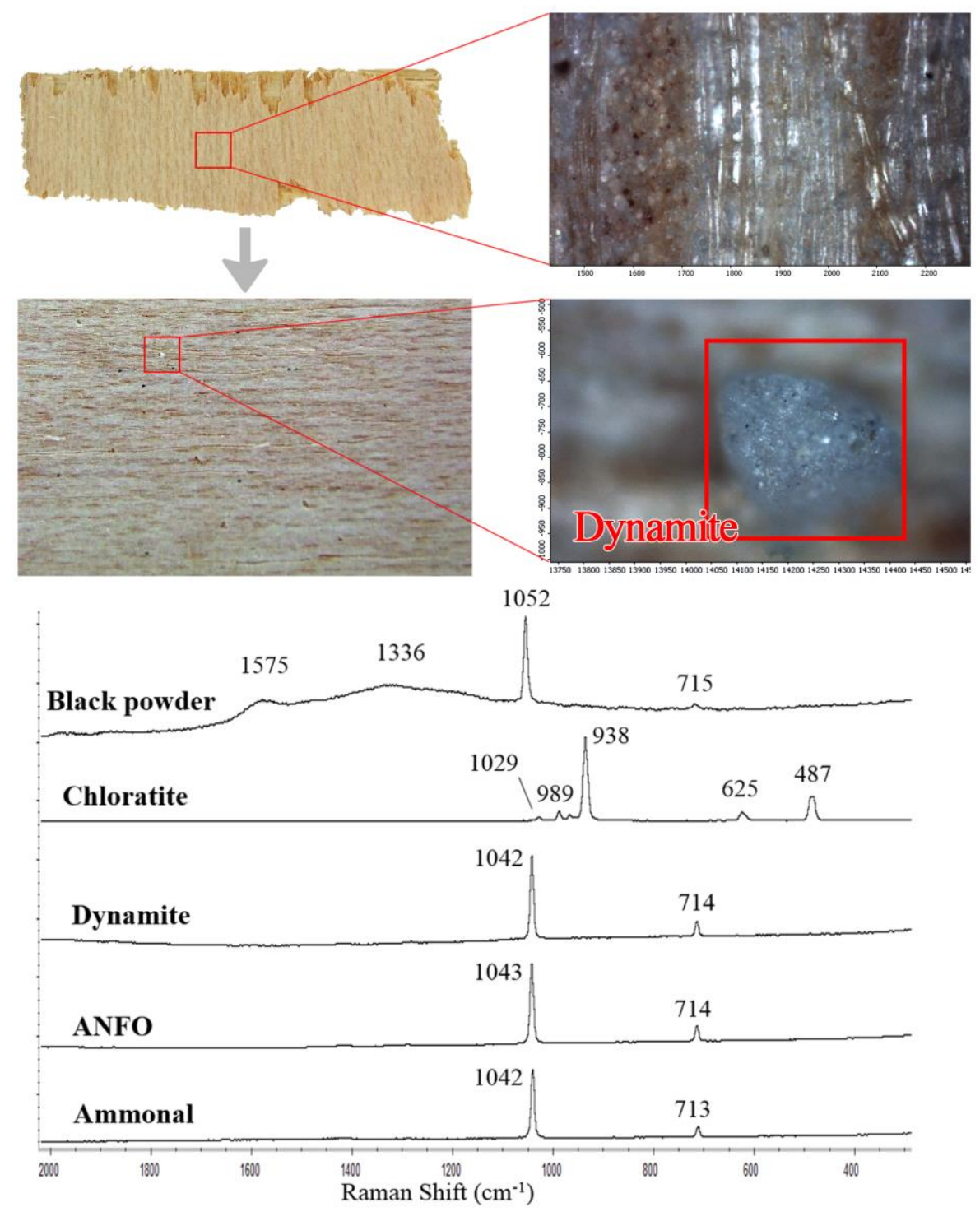

Supplementary Figure S3. Microscopic examination of plywood surface (above) and post-blast residues (below) and Raman spectra of the post-blast residues from the explosives detected on plywood collectors: black powder, chloratite, dynamite, ANFO and ammonal. Raman conditions as in Figure 1. 
In fact, the plywood collectors provided, as plastic bags, the best results since post-blast residues from the five explosives were detected on them. In particular, post blast particles from chloratite and ANFO were detected in the 3 replicates, post-blast particles from black powder and ammonal were detected in 2 of the 3 replicates and post-blast particles from dynamite were detected only in 1 of the 3 replicates as summarized in Table 2.

3.2.2.2. Chipboard. Chipboard substrates provided a highly heterogeneous surface when they were observed with the microscope as displayed in Supplementary Figure S4. This excessive heterogeneity containing numerous and different components hindered the detection of post-blast particles from the explosive. Even so, as indicated in Table 2, postblast particles from black powder and chloratite were identified on the 3 replicates of chipboard. However, post-blast particles from dynamite, ANFO and ammonal were not detected in any of the 3 replicates.

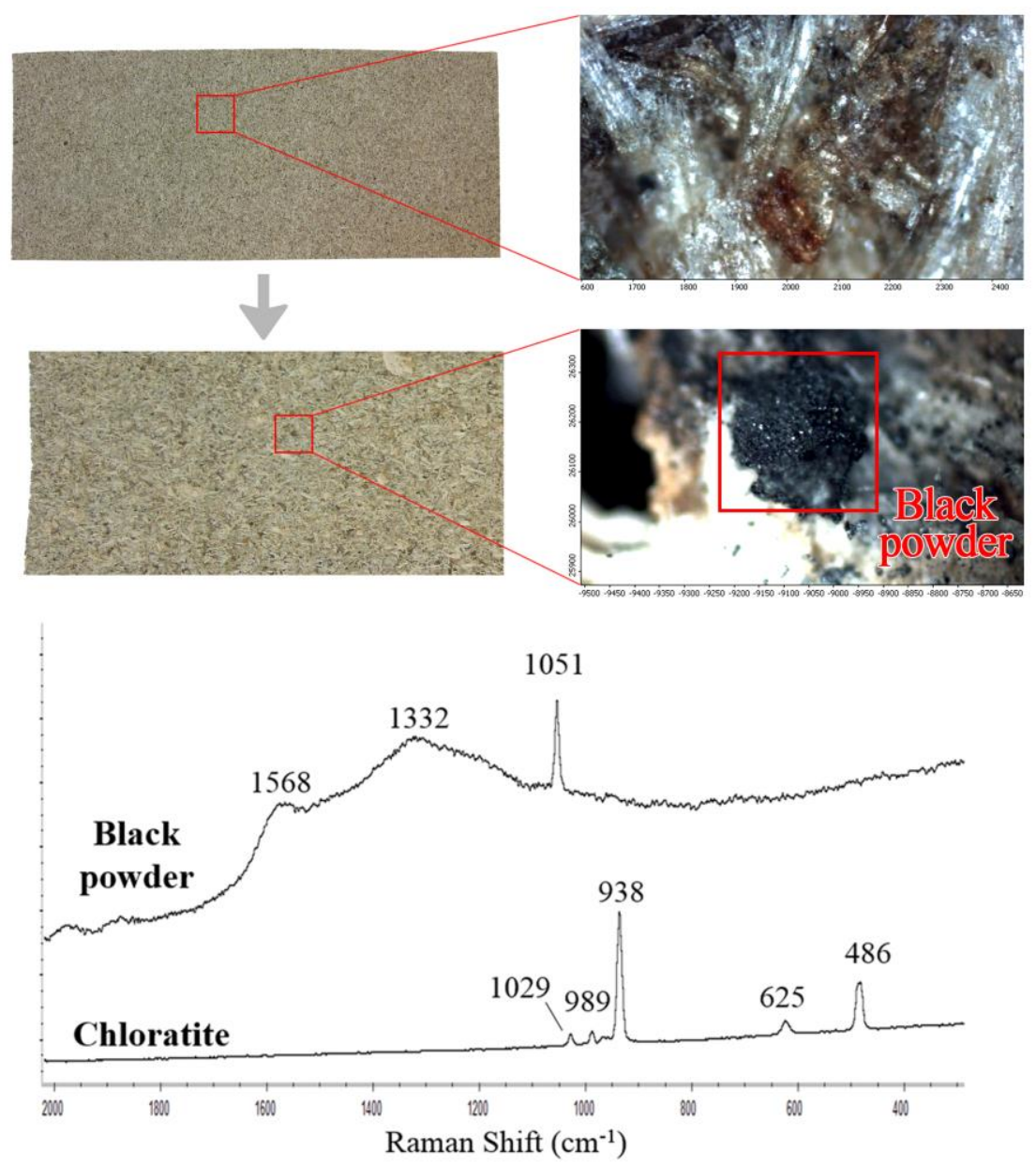

Supplementary Figure S4. Microscopic examination of chipboard surface (above) and post-blast residues (below) and Raman spectra of the post-blast residues from the two explosives detected on chipboard collectors: black powder and chloratite. Raman conditions as in Figure 1. 
3.2.2.3. Cardboard. Cardboard substrates were also heterogeneous though not as much as chipboard. In particular, the brown large homogeneous areas within the cardboard samples also contained small white-colored components which, to the naked eye, could be sometimes confused with post-blast particles, as displayed in Supplementary Figure S5. Despite that, using the Raman microscope, post-blast particles from all the explosives except dynamite were identified on cardboard. As collected in Table 2, post-blast particles from black powder and chloratite were identified on the 3 replicates whereas post-blast particles from ANFO and ammonal were identified only in 2 of the 3 replicates.

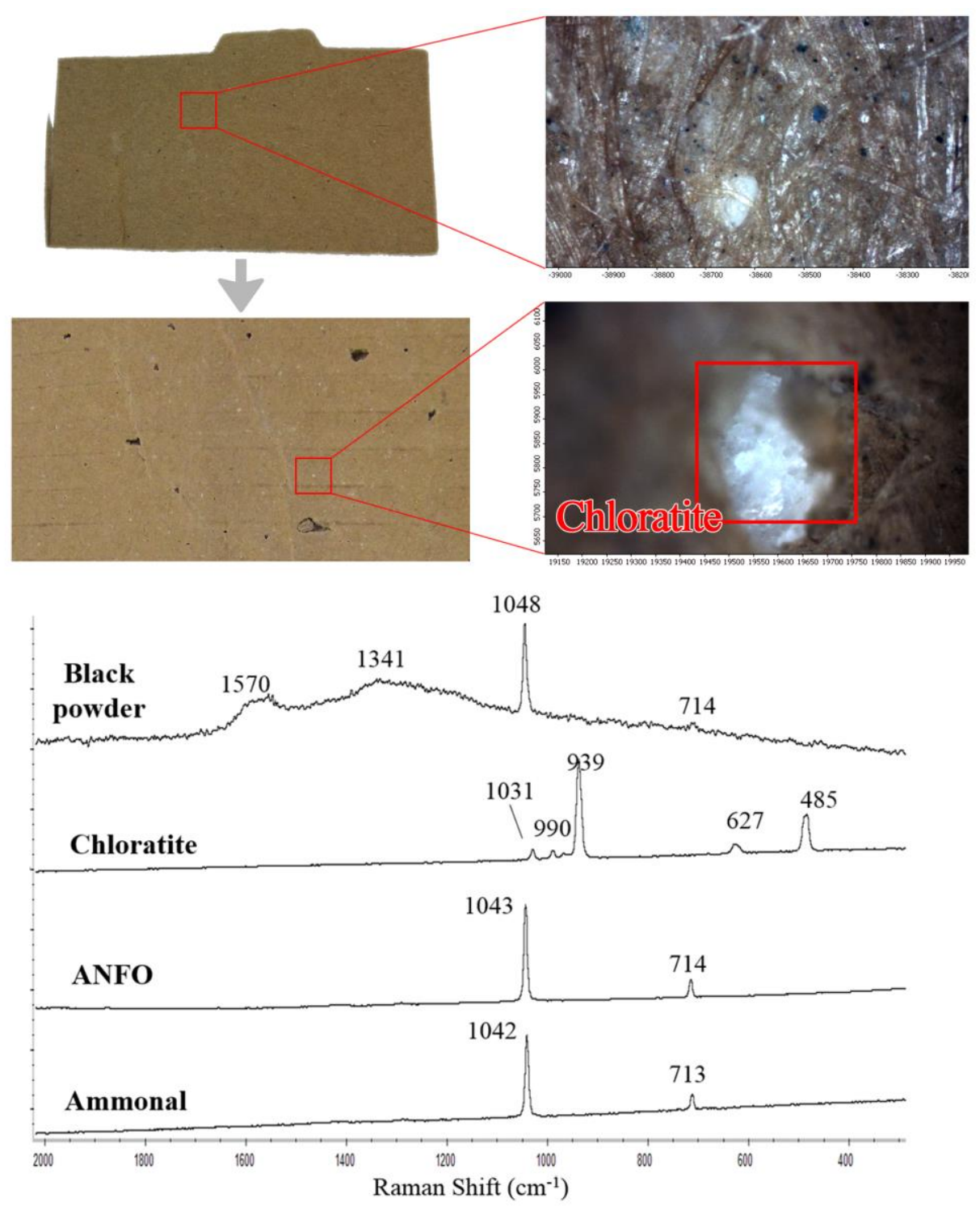

Supplementary Figure S5. Microscopic examination of cardboard surface (above) and post-blast residues (below) and Raman spectra of the post-blast residues from the four explosives detected on cardboard collectors: black powder, chloratite, ANFO and ammonal. Raman conditions as in Figure 1. 


\subsubsection{Highly irregular surfaces}

3.2.3.1. Tyre. Tyre samples were homogeneous in colour (black) but they offered highly rough and irregular surfaces due to their pattern and tread. In addition, they had been previously used, therefore, they were heterogeneously bald and they had some dirtiness and residues as evidenced in Supplementary Figure S6. To the naked eye, these residues were sometimes confused with post-blast residues. As previously mentioned (see Materials), only one tyre (one replicate) per explosion was used. With regards to the results (see Table 2), only post-blast particles from chloratite and ANFO were identified on tyre. No post-blast particles from black powder, dynamite or ammonal were detected.
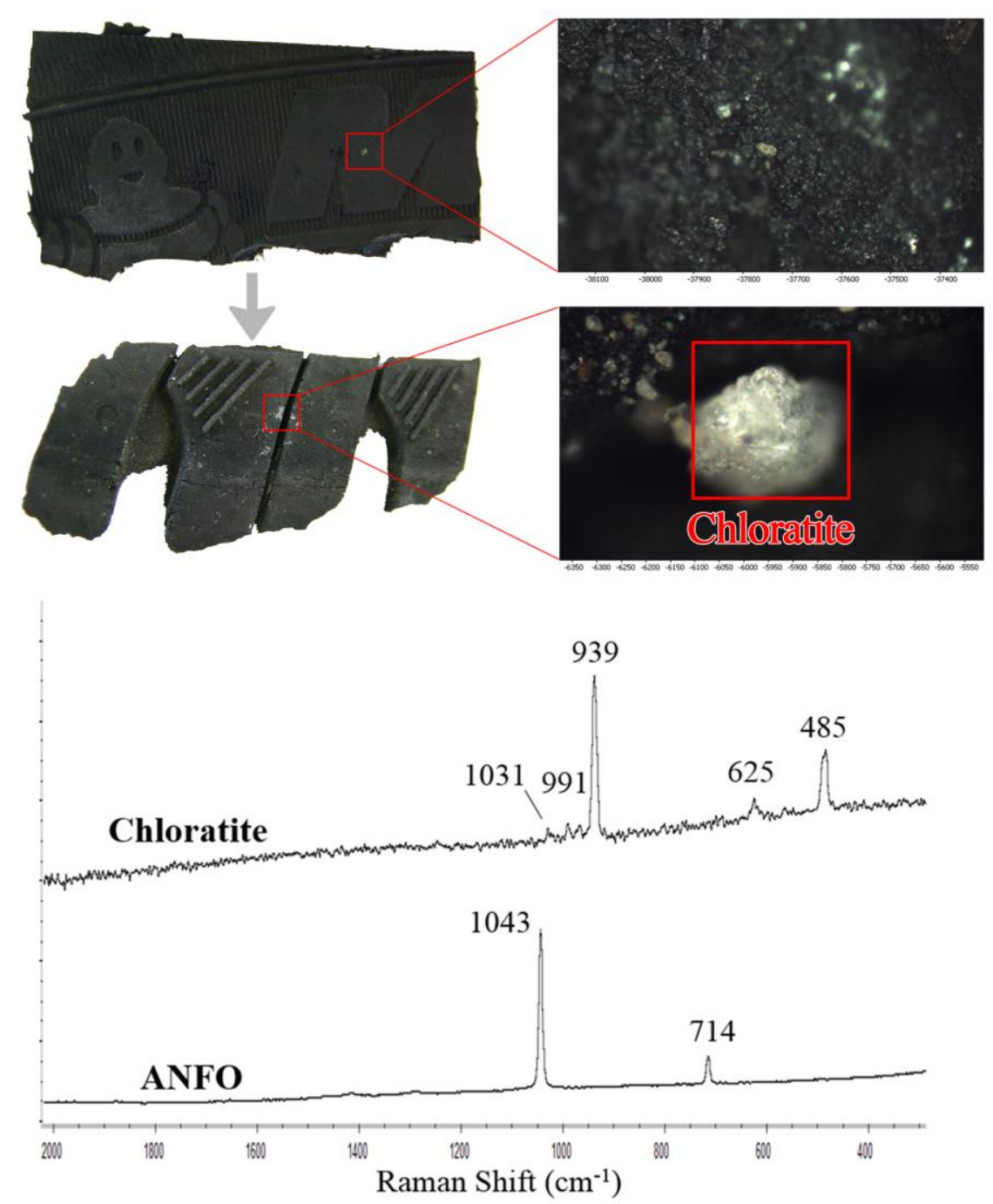

Supplementary Figure S6. Microscopic examination of tyre surface (above) and post-blast residues (below) and Raman spectra of the post-blast residues from the two explosives detected on tyre: chloratite and ANFO. Raman conditions as in Figure 1. 
3.2.3.2. Brick. Bricks provided heterogeneous, rough and highly irregular surfaces alternating flat areas and longitudinal grooves of orange colour with small white particles as shown in Supplementary Figure S7. To the naked eye, these particles were sometimes confused with post-blast particles from explosives, as occurred with cardboard. In addition, brick provided a highly intense Raman spectrum which hindered the Raman determination of those tiny post-blast particles not big enough to display their Raman spectra over the background. In fact, only post-blast residues from black powder were identified on bricks (on the three replicates). However, post-blast particles from any of the other four explosives (chloratite, dynamite, ANFO and ammonal) were not detected on any of the 3 replicates as summarized in Table 2.
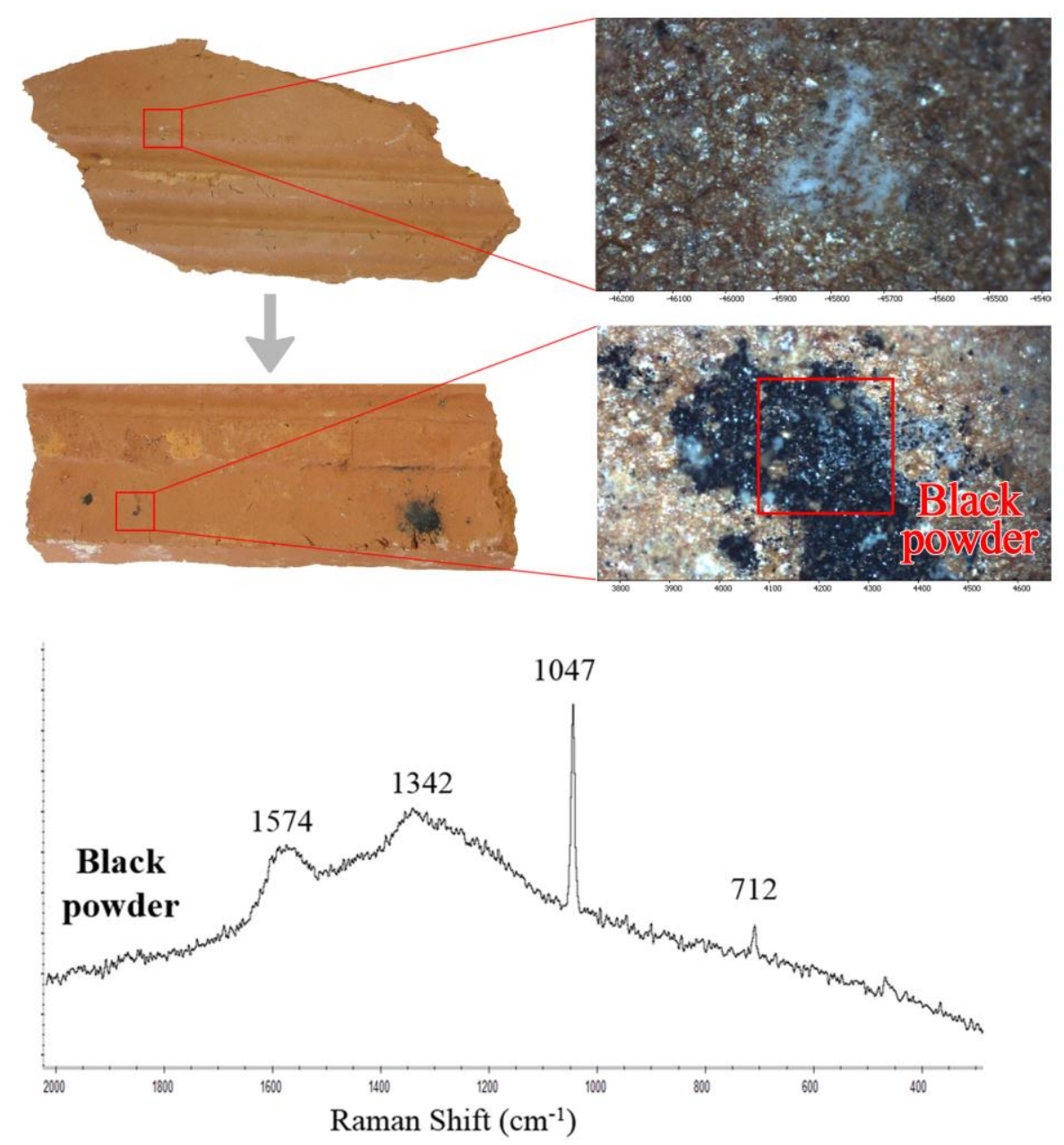

Supplementary Figure S7. Microscopic examination of brick surface (above) and post-blast residues (below) and Raman spectra of the post-blast residues from the unique explosive detected on brick: black powder. Raman conditions as in Figure 1. 
3.2.3.3. Plaster board. Plaster board substrates were white and quite homogeneous in color, but they offered a highly irregular surface consisting of numerous orifices as displayed in Supplementary Figure S8. The white surface of plaster board greatly hindered the detection of white post-blast particles from explosives. In fact, post-blast particles from black powder were easily identified on the three replicates whereas postblast particles from the other four explosives were hardly detected. According to Table 2 , post-blast particles from chloratite and ANFO were detected in 1 of the 3 replicates whereas post-blast particles from dynamite and ammonal were not detected in any of the replicates.

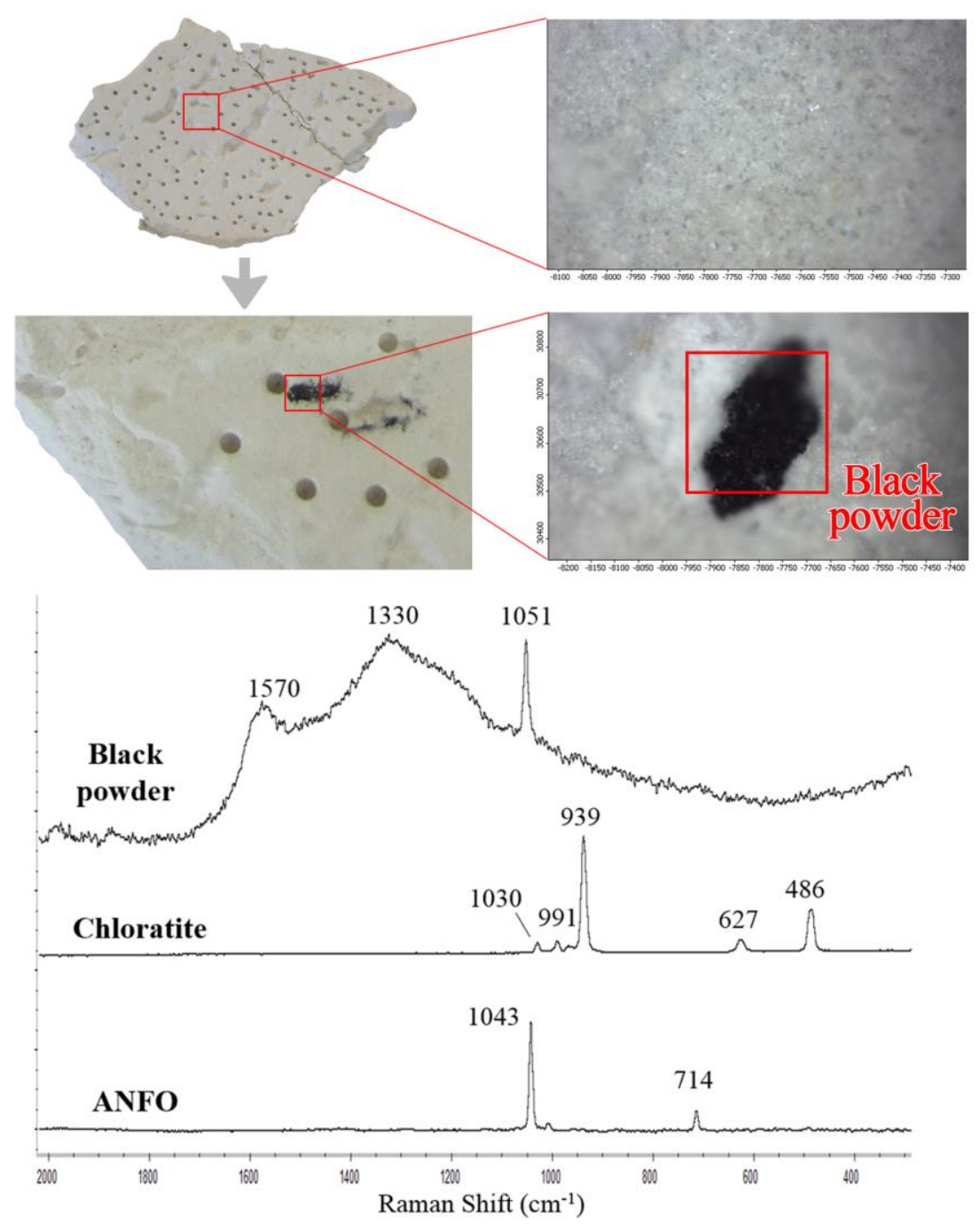

Supplementary Figure S8. Microscopic examination of plasterboard surface (above) and postblast residues (below) and Raman spectra of the post-blast residues from the three explosives detected on plasterboard collectors: black powder, chloratite and ANFO. Raman conditions as in Figure 1. 
3.2.3.4. Cotton fabric. Cotton fabrics were white and homogeneous except for the highly irregular surface, caused by the interlaced fibers, as displayed in Supplementary Figure S9. In fact, post-blast residues were mostly trapped within the fibers and the microscopic detection and Raman analysis became difficult and time-consuming. As shown in Table 2 , post-blast particles from black powder were identified in 2 of the 3 replicates and postblast particles from chloratite were detected in 1 of the replicates. Post-blast particles from dynamite, ANFO and ammonal were not detected in any of the replicates.

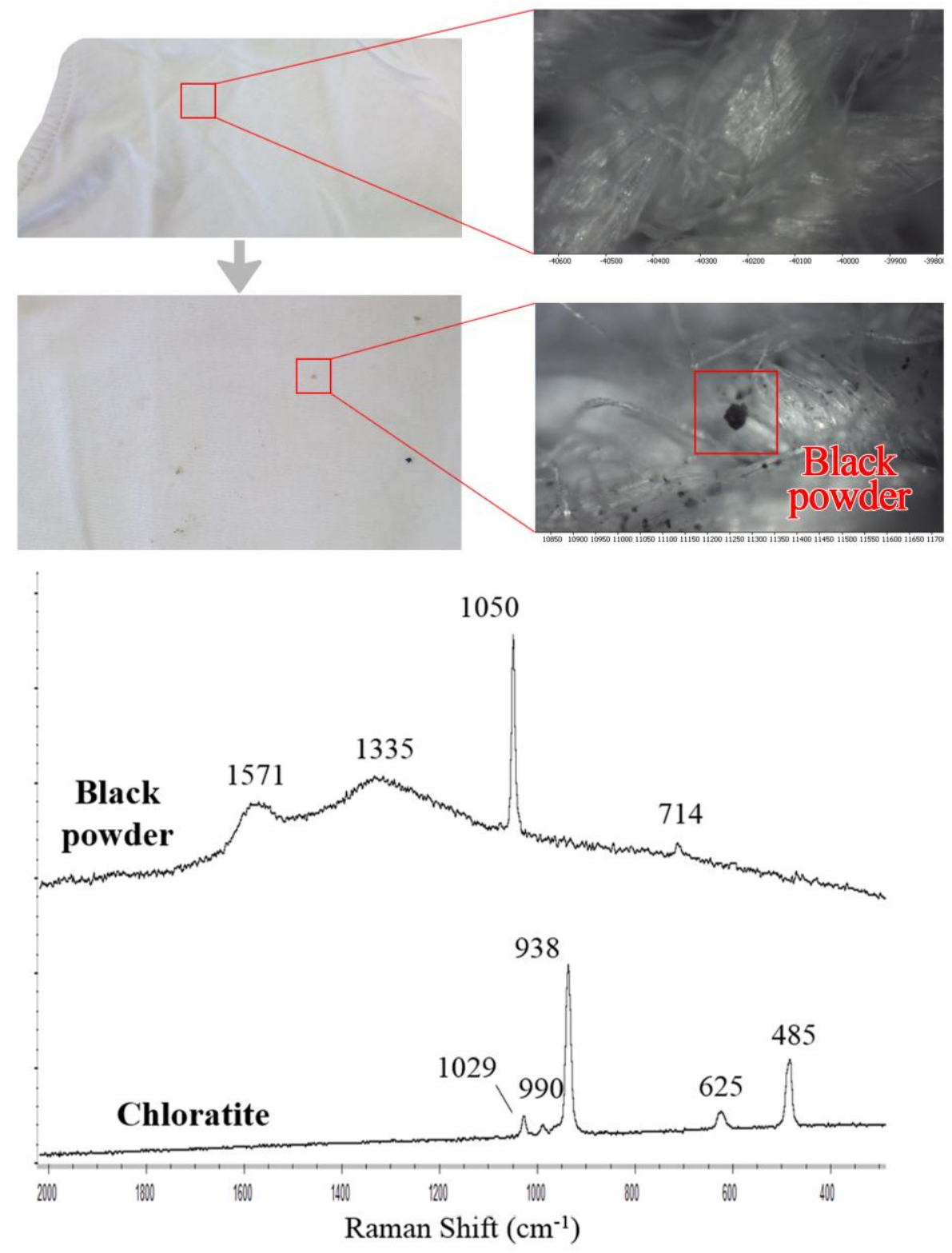

Supplementary Figure S9. Microscopic examination of cotton surface (above) and post-blast residues (below) and Raman spectra of the post-blast residues from the two explosives detected on cotton collectors: black powder and chloratite. Raman conditions as in Figure 1. 


\subsubsection{Biological surface}

3.2.4.1. Pig meat. The surface of pig meat was highly heterogeneous, as shown in Supplementary Figure S10. Post-blast residues were mostly detected on the skin, though some areas of the skin were burnt. In addition, these samples started to decompose after the explosion even though they were kept in the refrigerator when they were not being analyzed. In fact, pig meat samples provided the worst results. In particular, post-blast particles of charcoal from black powder were the unique particles detected on these samples. Even potassium nitrate was not detected, as displayed in Supplementary Figure S10. No post-blast particles from the other four explosives were detected. This result is probably explained by the fact that pig meat has a high water content which would have completely or partially dissolved the particles of inorganic salts in such a way that they were not already detectable by microscopy. Furthermore, the own degradation of meat (even in the refrigerator) could have also degraded the inorganic salts.
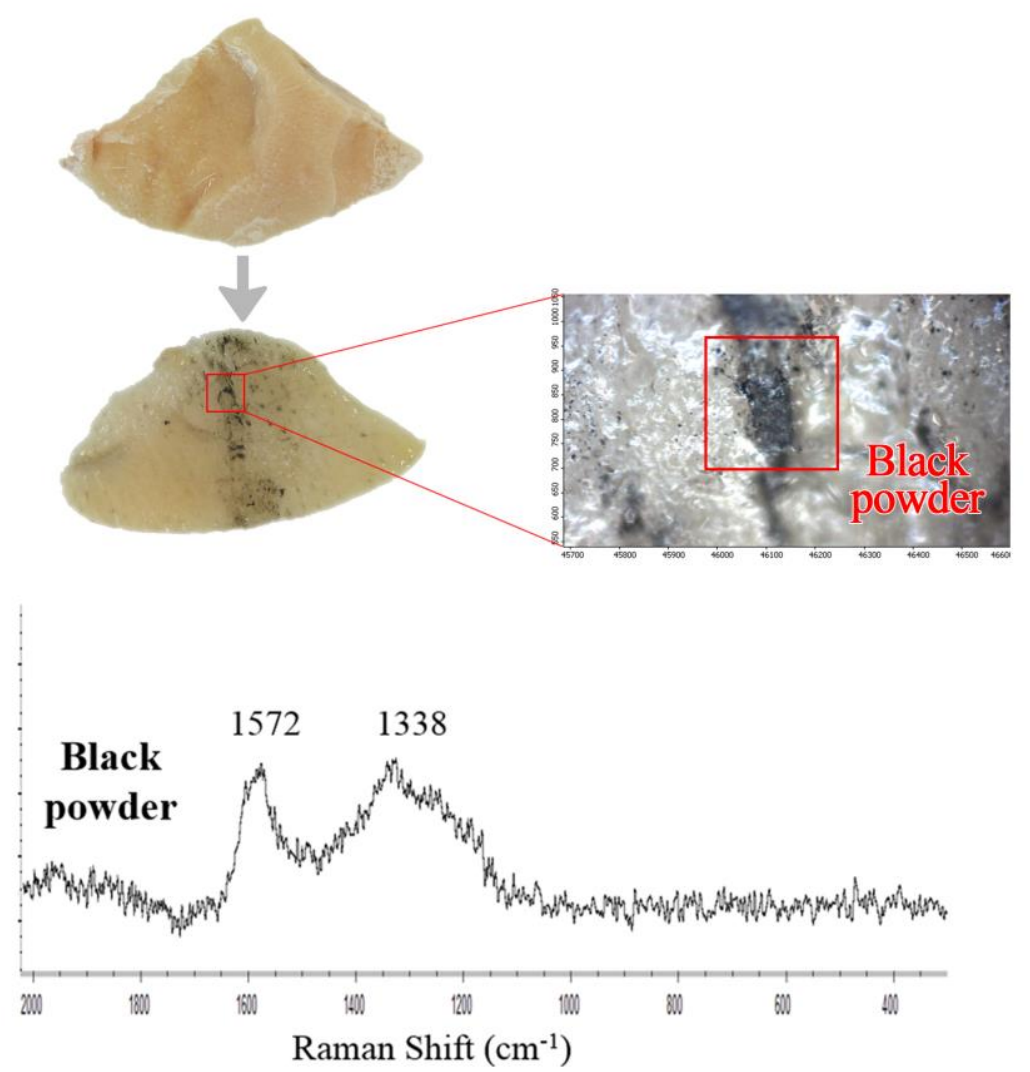

Supplementary Figure S10. Microscopic examination of post-blast residues on pig meat surface and Raman spectra of the post-blast residues from the unique explosive detected on pig meat collectors: black powder. Raman conditions as in Figure 1. 
Finally, some general outcomes regarding the explosives were drawn. It should be highlighted that charcoal and potassium nitrate from black powder were detected in all materials except for tyre; sodium chlorate from chloratite was detected for all materials except for brick and pig meat; ammonium nitrate from ANFO was detected in all materials except for chipboard, brick, cotton fabric and pig meat; ammonium nitrate from ammonal was detected in glass, plastic bag, plywood and cardboard; and ammonium nitrate from dynamite was only detected in plastic bag and plywood. In summary, postblast particles from dynamite were detected in 2 of the 11 materials, ammonal in 4 of the 11 materials, ANFO in 7 of the 11 materials, chloratite in 9 of the 11 materials and black powder in 10 of the 11 materials.

In addition, both the best and the worst materials as collectors of post-blast residues detectable by Raman microscopy were assessed. Plastic bag and plywood offered the best results because post-blast non-reacted particles from the five explosives were detected on them. On the contrary, brick and pig meat provided the worst results because only postblast particles from black powder were detected on them. According to the number of positive/ negative results achieved for the five explosives, the eleven materials (collectors) were listed as follows: Plastic bag and plywood > glass and cardboard > steel and plasterboard > chip-board, tyre and cotton fabric > brick and pig meat. It should be noted that this list had resulted from the obtained results which depend on the combination of two factors: the material's efficiency to collect post blast residues and the advantages/drawbacks of that materials to be analyzed by Raman microscopy.

Therefore, that means that the best materials such as plastic bag and plywood were competent for both factors. However, it does not mean that the worst materials were necessarily unsatisfactory to both factors. For instance, cotton fabric was demonstrated to be highly suitable to trap post-blast residues within the fibers, but it provided bad results, which are likely attributed to the clear difficulty of detecting the post-blast particles across the fibers by Raman microscopy. Thus, post-blast residues on cotton may be more accurately analyzed using other techniques or subjected to some extraction methodology. 


\section{Conclusions}

Enough spectral resolution is essential to differentiate potassi- um and ammonium nitrates, whose Raman bands are character- ized by having a slight Raman shift of 6-8 $\mathrm{cm}^{-1}$. This can be tested by means of a rapid and simple strategy which may be easily performed with the available Raman spectrometer to check whether both characteristic bands can be simultaneously resolved.

Regarding the appropriateness of each material as collector of post-blast explosive traces, it should be remarked the high quantity of post-blast non-reacted particles from explosives found inside plastic bags, which makes these collectors highly recommendable for the identification of explosive traces in post-blast evidence. In addition, the evidence recovery process may be planned in order to recover first the most worthwhile materials (collectors) according to the reported results. In general, either homogeneous or heterogeneous surfaces were demonstrated to provide the best results whereas highly irregular surfaces and biological surfaces offered the highest difficulties. Thus, the best explosive trace collectors were listed as follows:

Plastic bag and plywood > glass and cardboard > steel and plasterboard > chipboard, tyre and cotton fabric $>$ brick and pig meat.

Considering that microscopy has been the technique used to look for the post-blast residues from explosives, it is understand-able that highly irregular surfaces offered a more unfriendly and problematic surface to this aim. In any case, if both homogeneous, heterogeneous and highly irregular materials contain post-blast residues from these explosives, the non-irregular surfaces should be easily and rapidly examined by confocal Raman microscopy whereas the highly irregular surfaces could be reserved for other sort of analysis such as capillary electrophoresis or ion chroma- tography (the analytical techniques commonly used in forensic laboratories to determine inorganic ions). Thus, the samples recovered during evidence recovery can be classified in different groups in order to be suitably analyzed using the most appropriate and informative technique in each case. 


\section{Acknowledgements}

The authors would like to acknowledge the Project HOME/2011/ ISEC/AG/4000002480 funded with the financial support of the Prevention of and Fight against Crime Programme from the European Commission-Directorate-General Home Affairs. This publication reflects the views only of the authors, and the European Commission cannot be held responsible for any use which may be made of the information contained therein. The authors greatly thank José Luis Ferrando and the Spanish EOD specialists, for the inestimable assistance to carry out the controlled explosions and the recovery evidence process. Félix Zapata would like to thank the Spanish Ministry of Education for his $\mathrm{PhD}$ research grant FPU014/00790.

\section{References}

[1] M. Marshall, J. Oxley, Explosives: the threats and the materials, in: M. Marshall, J.C. Oxley (Eds.), Aspects of Explosives Detection, Elsevier, Netherlands, 2009, pp. 11-26.

[2] J.T. Thurman, Practical Bomb Scene Investigation, Taylor \& Francis, Boca Raton, USA, 2006.

[3] H.T. Christen, P.M. Maniscalco, Weapons of mass effect-explosives, in: P.M. Maniscalco, H.T. Christen (Eds.), Homeland Security: Principles and Practice of Terrorism Response, Jones and Bartlett publishers, Sudbury, MA, USA, 2011, pp. $161-170$.

[4] U.S. Army, U.S. Army Explosives and Demolitions Handbook, Skyhorse Publishing Inc., Canada, 2010.

[5] J.B. Ledgard, The Preparatory Manual of Black Powder and Pyrotechnics, Lulu Press Inc., Seattle, Washington, 2006.

[6] S.J. Benson, C.J. Lennard, P. Maynard, D.M. Hill, A.S. Andrewe, C. Roux, Forensic analysis of explosives using isotope ratio mass spectrometry (IRMS) discrimination of ammonium nitrate sources, Sci. Justice 49 (2009) 73-80.

[7] N. Abdul-Karim, C.S. Blackman, P.P. Gill, E.M.M. Wingstedt, B.A.P. Reif, Postblast explosive residue - a review of formation and dispersion theories and experimental research, RSC Adv. 4 (2014) 54354-54371. 
[8] J. Cummins, J. Hull, K. Kitts, J.V. Goodpaster, Separation and identification of anions using porous graphitic carbon and electrospray ionization mass spectrometry: application to inorganic explosives and their post blast residues, Anal. Methods 3 (2011) 1682-1687.

[9] C. Martín-Alberca, F. Zapata, H. Carrascosa, F.E. Ortega-Ojeda, C. García-Ruiz, Study of consumer fireworks post-blast residues by ATR-FTIR, Talanta 149 (2016) 257-265.

[10] F. Zapata, C. García-Ruiz, Determination of nanogram microparticles from explosives after real open-air explosions by confocal Raman microscopy, Anal. Chem. 88 (2016) 6726-6733.

[11] J.P. Hutchinson, C. Johns, M.C. Breadmore, E.F. Hilder, R.M. Guijt, C. Lennard, G. Dicinoski, P.R. Haddad, Identification of inorganic ions in post-blast explosive residues using portable CE instrumentation and capacitively coupled contactless conductivity detection, Electrophoresis 29 (2008) 4593-4602.

[12] N. Abdul-Karim, C.S. Blackman, P.P. Gill, R.M. Morgan, L. Matjacic, R. Webb, W. H. Ng, Morphological variations of explosive residue particles and implications for understanding detonation mechanisms, Anal. Chem. 88 (2016) 3899-3908.

[13] G.W. Dicinoski, R.A. Shellie, P.R. Haddad, Forensic identification of inorganic explosives by ion chromatography, Anal. Lett. 39 (4) (2006) 639-657.

[14] C. Johns, R.A. Shellie, O.G. Potter, J.W. O’Reilly, J.P. Hutchinson, R.M. Guijt, M.C. Breadmore, E.F. Hilder, G.W. Dicinoski, P.R. Haddad, Identification of homemade inorganic explosives by ion chromatographic analysis of postblast residues, J. Chromatogr. A 1182 (2008) 205-214.

[15] M. Pumera, Analysis of explosives via microchip electrophoresis and conventional capillary electrophoresis: a review, Electrophoresis 27 (2006) 244 256.

[16] J.P. Hutchinson, C.J. Evenhuis, C. Johns, A.A. Kazarian, M.C. Breadmore, M. Macka, E.F. Hilder, R.M. Guijt, G.W. Dicinoski, P.R. Haddad, Identification of inorganic improvised explosive devices by analysis of postblast residues using portable capillary electrophoresis instrumentation and indirect photometric detection with a light-emitting diode, Anal. Chem. 79 (2007) 70057013. 
Mineta, P. Gareil, Identification and determination of inorganic anions in real extracts from pre- and post-blast residues by capillary electrophoresis, J. Chromatogr. A 1217 (2010) 6971-6978.

Haddad, M.C. Breadmore, Identification of inorganic improvised explosive devices using sequential injection capillary electrophoresis and contactless conductivity detection, Anal. Chem. 83 (2011) 9068-9075.

[19] C. Sarazin, N. Delaunay, C. Costanza, V. Eudes, P. Gareil, Capillary electrophoresis analysis of inorganic cations in post-blast residue extracts applying a guanidinium-based electrolyte and bilayer-coated capillaries, Electrophoresis 32 (2011) 1282-1291.

[20] C. Martín-Alberca, M.A. Fernández de la Ossa, J. Saiz, J.L. Ferrando, C. García-Ruiz, Anions in pre- and post-blast consumer fireworks by capillary electrophoresis, Electrophoresis 35 (2014) 3272-3280.

[21] B. Zachhuber, G. Ramer, A. Hobro, E.H. Chrysostom, B. Lendl, Stand-off Raman spectroscopy: a powerful technique for qualitative and quantitative analysis of inorganic and organic compounds including explosives, Anal. Bioanal. Chem. 400 (2011) 2439-2447.

[22] S. Wallin, A. Pettersson, H. Önnerud, H. Östmark, M. Nordberg, E. Ceco, A. Ehlerding, I. Johansson, P. Käck, Possibilities for standoff Raman detection applications for explosives, Proc. SPIE 8358 (2012) 83580P/1-83580P/9.

[23] M.R. Almeida, D.N. Correa, J.J. Zacca, L.P.L. Logrado, R.J. Poppi, Detection of explosives on the surface of banknotes by Raman hyperspectral imaging and independent component analysis, Anal. Chim. Acta 860 (2015) 1522.

[24] F. Zapata, M.A. Fernández de la Ossa, E. Gilchrist, L. Barron, C. GarcíaRuiz, Progressing the analysis of improvised explosive devices: comparative study for trace detection of explosive residues in handprints by Raman spectroscopy and liquid chromatography, Talanta 161 (2016) 219-227.

[25] J. Kuula, H. Rinta, I. Pölönen, H.H. Puupponen, M. Haukkamäki, T. Teräväinen, Detecting explosive substances by the IR spectrography, Proc. SPIE 9073 (2014) 90730Q/1-90730Q/12. 
[26] B. Bozzini, V. Romanello, C. Mele, F. Bogani, A SERS investigation of carbon steel in contact with aqueous solutions containing BenzylDiMethylPhenylAmmonium Chloride, Mater. Corros. 58 (2007) 20-24. 